Saudi Journal of Medical and Pharmaceutical Sciences

Abbreviated Key Title: Saudi J Med Pharm Sci

ISSN 2413-4929 (Print) |ISSN 2413-4910 (Online)

Scholars Middle East Publishers, Dubai, United Arab Emirates

Journal homepage: https://saudijournals.com

Case Report

\title{
Posttraumatic Right Diaphragmatic Rupture with Delayed Hepatic Hernia: Two Case Reports
}

\author{
Mohammed Najih ${ }^{1 *}$, Hicam Laraqui ${ }^{1}$, Nouredine Njoumi ${ }^{1}$, Mohamed Laaroussi ${ }^{1}$, Mountassir Moujahid ${ }^{1}$, Aziz Zentar ${ }^{1}$ \\ ${ }^{1}$ Department of General Surgery, Mohamed V Military Teaching Hospital, Mohamed V-Souissi University, Rabat, Morocco
}

\begin{tabular}{ll}
\hline DOI: $10.36348 /$ sjmps.2021.v07i02.009 & | Received: 13.02.2021 | Accepted: 22.02 .2021 | Published: 26.02 .2021 \\
*Corresponding author: Mohammed Najih &
\end{tabular}

Abstract

The post-traumatic right diaphragmatic hernia associated with liver dislocation often goes unnoticed because it complicates violent trauma, but most times remains asymptomatic. It is recommended discussing systematically the diagnostic in case of closed abdominal chest trauma or after a bladed weapon wound in order to prevent its serious complications. We report two cases of post-traumatic diaphragmatic hernia associated with a liver luxation compiled in our service.

Keywords: Posttraumatic, Hepatic Hernia.

Copyright () 2021 The Author(s): This is an open-access article distributed under the terms of the Creative Commons Attribution 4.0 International License (CC BY-NC 4.0) which permits unrestricted use, distribution, and reproduction in any medium for non-commercial use provided the original author and source are credited.

\section{INTRODUCTION}

Posttraumatic diaphragmatic hernia associated with liver dislocation often goes unnoticed because it complicates violent trauma, but mostly it remains asymptomatic. It is recommended discussing this diagnosis systematically after an abdominal thoracic blunt injuries or a bladed weapon in order to prevent for severe complications.

\section{Patients and ObServations}

\section{Case 1:}

A 45-year-old man admitted for a right chest pain with dyspnea evolving for two months impeding his daily activities.

In these stories, we note a highway accident occurred three months ago causing pelvic fractures with a fracture of the seventh, 8th and 9th ribs. An orthopedic treatment established in another hospital with good clinical outcome.

Chest X-ray showed a rise of the right diaphragm with air-fluid levels in the right chest suggestive of diaphragmatic hernia (figure1). The CT scan showed a presence of the bowel and a portion of liver in the chest, confirming the diagnosis of diaphragmatic hernia (figure 2).

The intraoperative exploration by laparotomy revealed the passage into the thorax a part of the colon, omentum and a portion of liver. After the careful release of adhesions, the reduction was easy, the liver was returned to the abdomen, the tear extending was 12 centimeters, the edges of the defect were approximated using interrupted silk tied, and a prosthetic strengthening by a patch of Vicryl is realized. The patient was discharged on the third day without complication. He is presently well on a follow-up of 19 months with a good clinical and radiological evolution.

\section{CASE 2}

72-year-old man admitted to emergency for exertional dyspnea with intense cough preventing supine position, waking the patient in full night to get in half-sitting position.

In these stories, there is a road accident occurred twenty years ago causing chest pain that evolved well under medical treatment. Chest X-ray showed an ascent of right diaphragmatic dome (figure3). A CT scan confirmed the diagnosis of diaphragmatic hernia showing the presence of small bowel, the right colon and the liver in the thorax (figure4).

Right thoracotomy was done through 6th intercostal space. The liver, right colon and the small bowel have been reduced into the abdomen cavity. The diaphragm was repaired with interrupted sutures using non-absorbable thread and reinforced with resorbable Vicryl mesh. Chest drain was put and thoracotomy closure was done (figure 5, 6, 7). The patient is much improved after surgery and he was discharged ten days 
after. The follow up were simple with a good clinical and radiological evolution.
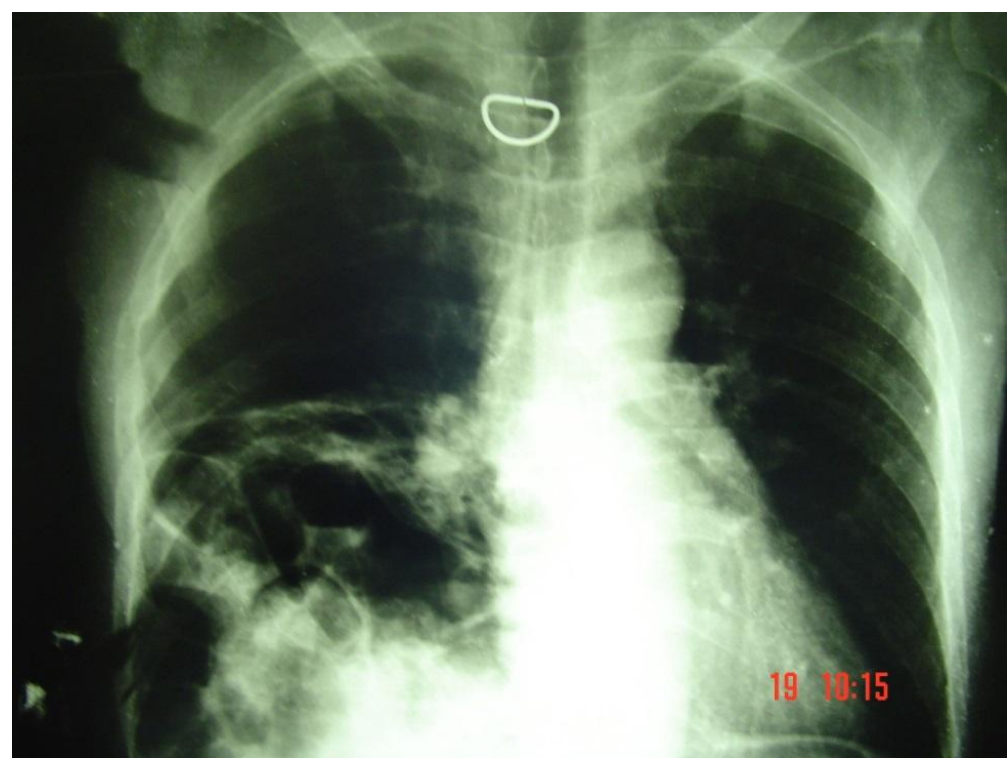

Fig-1: Chest X-ray showed a rise of the right diaphragm with air-fluid levels in the right chest suggestive of diaphragmatic hernia

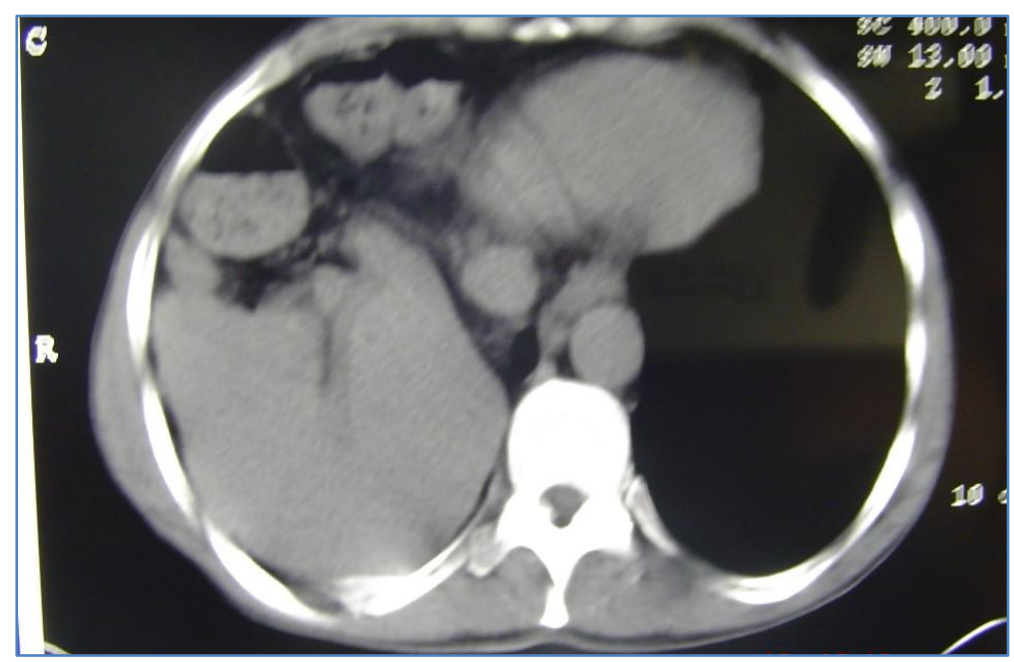

Fig-2: CT scan showed a presence of the bowel and a portion of liver in the chest, confirming the diagnosis of diaphragmatic hernia

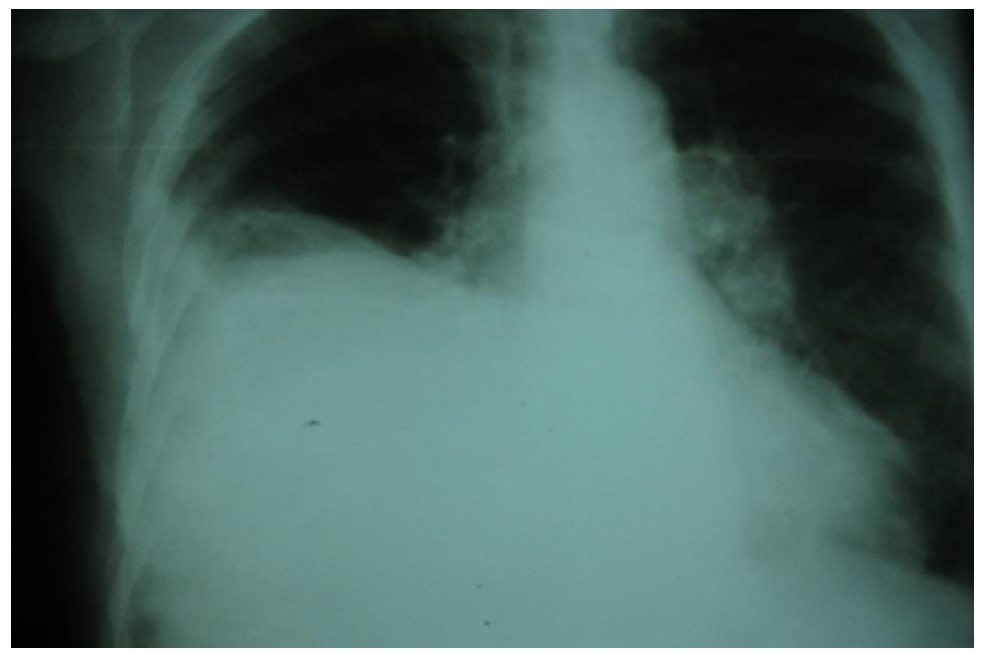

Fig-3: Chest radiography showed an ascent of the right diaphragmatic dome 
Mohammed Najih et al., Saudi J Med Pharm Sci, Feb, 2021; 7(2): 130-134

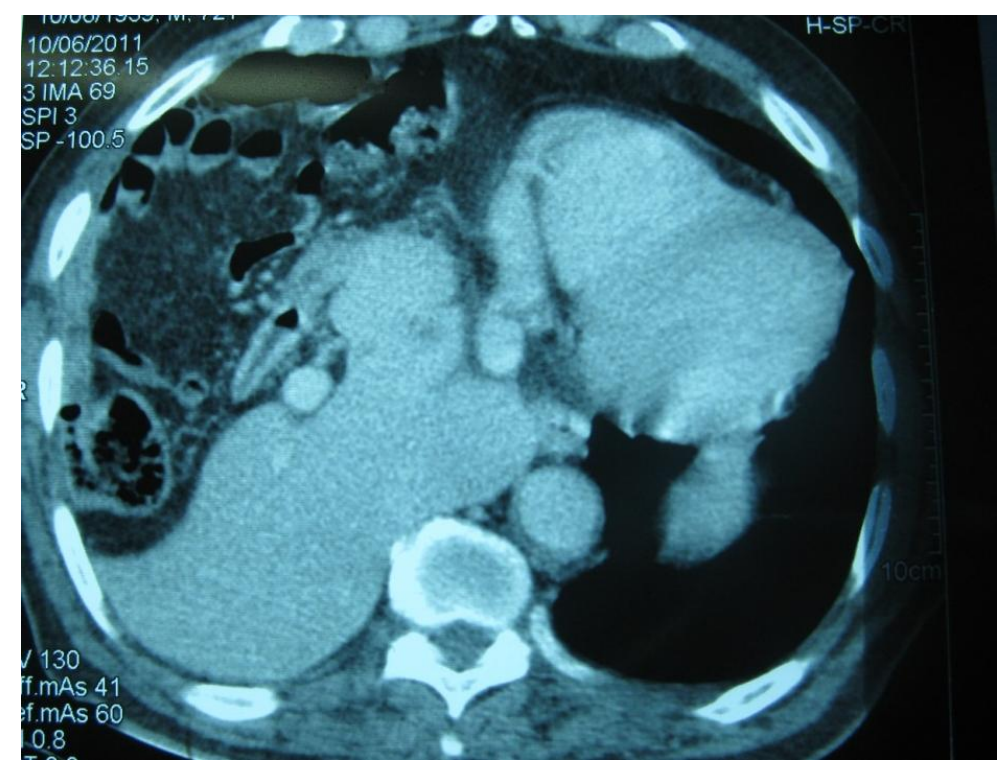

Fig-4: CT scan showing the presence of the intestine, the right colon and the intra thoracic liver herniation

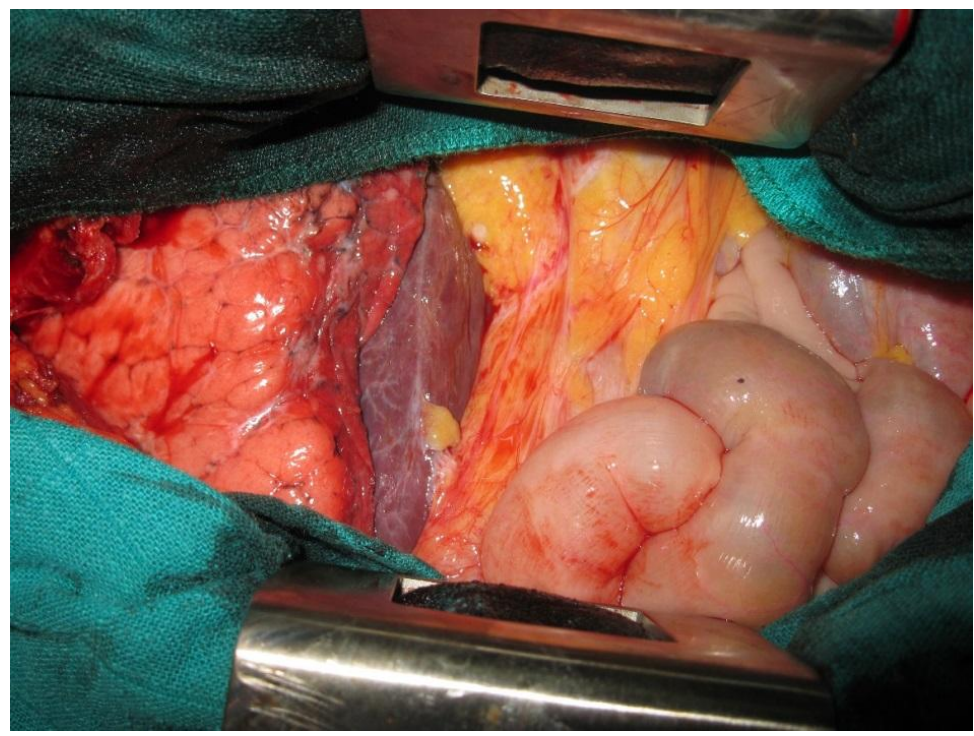

Fig-5: Operating view showing the presence in intra thoracic of the liver, the small intestine and the right colon

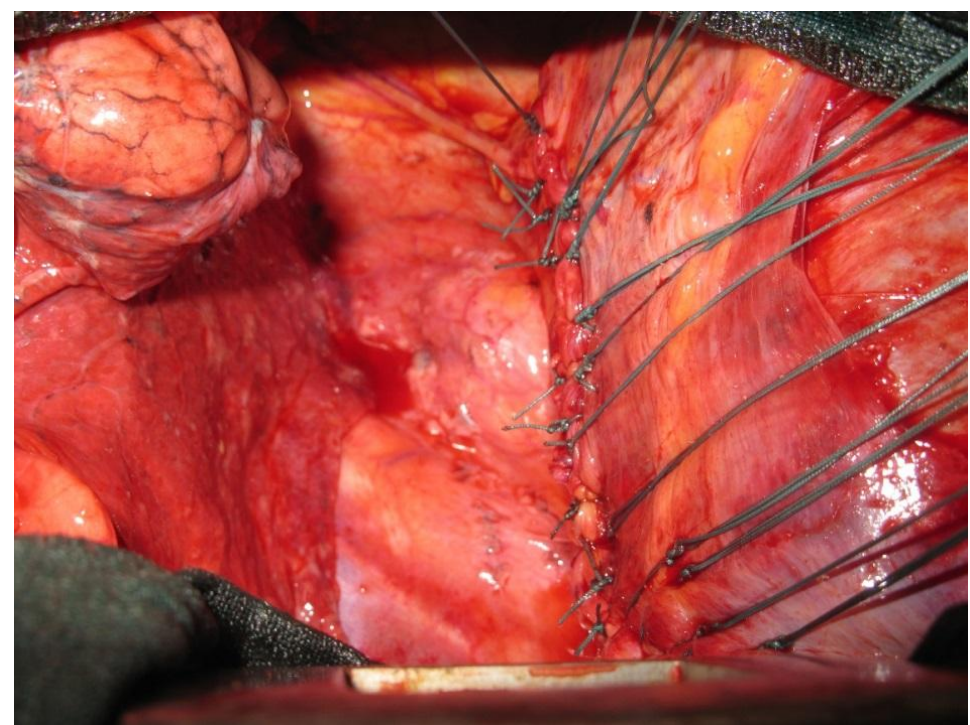

Fig-6: Suture of the diaphragmatic breach after reduction of herniated organs 


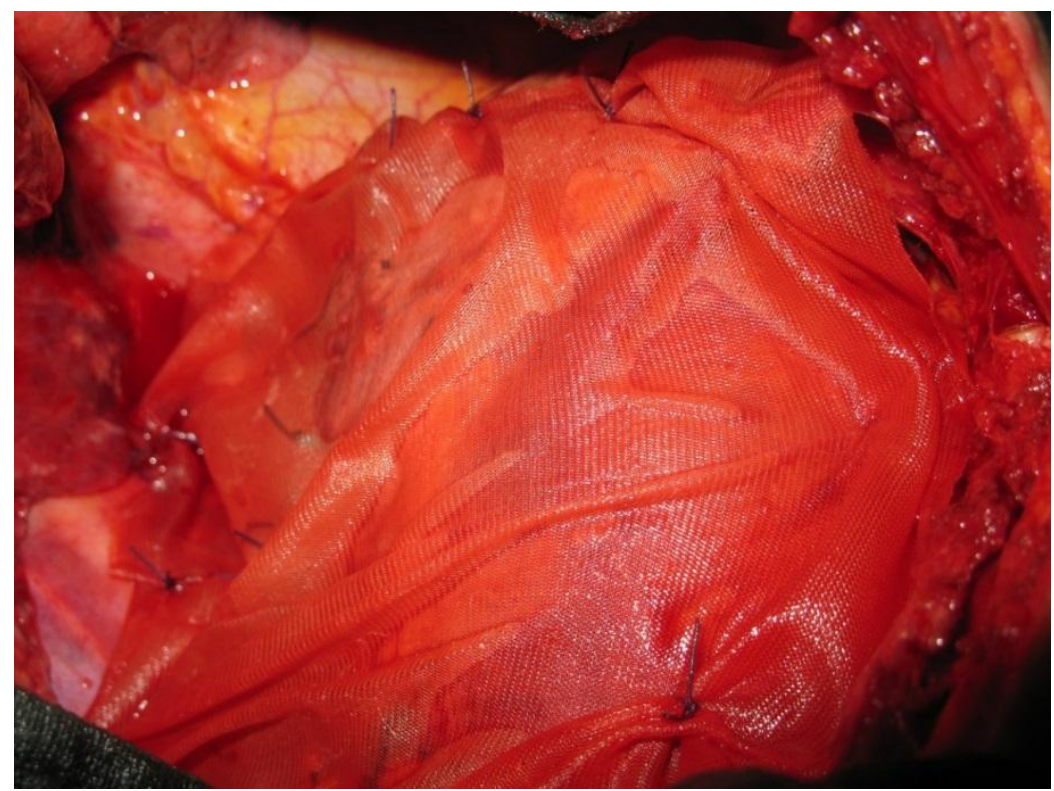

Fig-7: Strengthening of the suture of the diaphragmatic breach by prosthetic material

\section{DISCUSSION}

A hernia is a confined mass trained by an organ or a part of an organ taken out of the cavity that contains it by a natural or accidental defect. The diaphragmatic hernia is the exit of an organ of the abdominal cavity towards the thoracic cavity, it can be congenital or acquired. The diagnosis of diaphragmatic hernia secondary to trauma remains still late in spite of the contribution of the radiology. In 18 in $50 \%$ of the cases, the diagnosis is made a distance from the causal trauma [1]. The extension of appearance varies of a few months in more than 30 years [2].

Posttraumatic diaphragmatic hernia concern 2 $\%$ of severe chest and abdominal trauma [2]. The trauma of the diaphragm is often represented by breaks. They correspond to a muscular breach of the dome that can complicate of an intra-thoracic exit of the abdominal viscera.

The frequency of the diaphragmatic lesions is variously estimated: $0,5 \%, 7 \%$ of isolated thoracic traumas [3]. 73, $88 \%$ of the diaphragmatic breaks during the closed traumas and $12 \mathrm{a} 23 \%$ during the open traumas [3].

The mechanism of the break is most of the time indirect by crushing, creating an abdominal or thoracic hyper-pressure. During the closed traumas, the diaphragmatic break is connected in $75 \%$ of the cases to a deformation of the lower opening of the thorax secondary to fractures of the lower ribs. The abdominal compression is a less frequent mechanism. In this case, the break is secondary in the pressure exercised by organs on the diaphragm. It should check for rupture of the bladder, which is the corollary of diaphragmatic rupture in the lower abdomen. The penetrating injuries account for about $25 \%$ of diaphragmatic hernia diagnosed [4]. Diaphragmatic hernia mainly located on the left (85à 95\%des case) $[3,5]$. On the right, the liver interposition seals the breach and opposes the passage of viscera. Their frequency can be considered between 15 et $50 \%$ of the cases [5] they are exceptionally bilateral (approximately 2\%) [5, 6]. The domes Ruptures are the most common. They generally measure 5 à $15 \mathrm{~cm}$. On the left, rising evisceration concerns essentially the stomach (80\%des case), the left colonic angle (70\%des case) and the spleen which can be broken or intact (30\%des case), exceptionally the kidney [2].

The clinical symptoms depend on early diagnosis. They are three phases: the early phase dominated by cardiorespiratory signs. Intermediate phase where the clinical signs can be absent or atypical (epigastria pain, vomiting, and digestive bleeding) [3] and the late phase that is most of the time is noisy in the form of an occlusive or perforated syndrome [3].

The chest $X$ ray can show an abnormal extra height of the diaphragmatic dome, the presence of airfluid level in the thorax, distortion or obliteration of the outline of the hemidiaphragm and contralateral movement of mediastinum evoking the diagnosis in 55 $\%$ of the cases $[3,7,8]$. Right diaphragm injuries are more difficult to detect on the radiograph. The liver serves to block the herniation of abdominal contents into the thorax. Herniation of the liver is often overlooked. The differential diagnosis for elevated right hemidiaphragm includes right lower lobe atelectasis, pleural effusion and pulmonary contusion [7].

Abdominal ultrasound can be useful for diagnosis. It allows observing the lack of movement of the diaphragm, the herniated viscera and can visualize 
the rupture as a more or less extensive interruption of the membrane $[9,10]$. CT scan can observe signs for a diaphragmatic rupture, as thickening and irregularity of the membrane sheet and visceral hernia [6] with a sensibility of $61 \%$ and a $87 \%$ specificity $[7,8]$.

The limitations of this review are linked to respiratory movements and spacing of the cuts. The helical scan improves the sensitivity $(71 \%)$ and specificity (100\%) of diagnosis [8]. the indication of the helical scanning with image reconstruction should be considered before any suspicion of diaphragmatic rupture.

MRI offers identical information to that of helical CT but with directs coronal and sagittal images and better spatial and contrast resolutions of anatomic structures [11]. However, MRI has limitations, including restricted patient access, cost and, lastly, MRI is currently unsuitable for acute emergency patients.

Current literature recommends that the immediate surgical management of TDR should be via an abdominal approach. This facilitates identification of associated intra-abdominal injuries, found in $30-70 \%$ of patients [12].

In delayed presentation and the absence of associated abdominal injuries, it appears that a right thoracotomy with liver reintegration into the abdomen and repair the breach with separated points of the nonabsorbable thread is the most common strategy for right diaphragmatic rupture. It allows, if necessary, the possible control of thoracic adhesions and the establishing of prosthetic materials [13].

\section{CONCLUSION}

The diagnosis of posttraumatic right diaphragmatic rupture with liver herniation still late in spite of the contribution of radiology. The surgical strategy at diagnosis is variable and it should be discussed case by case.

\section{REFERENCES}

1. Takongomo, S., Nko'amvene, S., Juino, A.G. (1993). Post diaphragmatic Hernias about tree recent observations. Médecine d'Afrique noire, 40: 42-46

2. Esquis, P., Osmak, L., Ognois, P., Goudet, P., \& Cougard, P. (2005, October). Thoracic kidney: congenital or traumatic origin?. In Annales de chirurgie (Vol. 131, No. 4, pp. 276-278).

3. Fung, H., Vickar, D.B. (1991). Traumatic rupture of the right hemi diaphragm with hepatic herniation. Real time ultrasound demonstration $J$ Ultrasound Med, 10: 295-298

4. Shah, R., Sabanathan, S., Mearns, A. J., \& Choudhury, A. K. (1995). Traumatic rupture of diaphragm. The Annals of thoracic surgery, 60(5), 1444-1449.

5. Simpson, J., Lobo, D.N., Shah, A.B. (2000). Traumatic diaphragmatic rupture: associated injuries and outcome. Ann $R$ Coll Surg Engl, 82: 97-100

6. Boulanger, B. R., Kearney, P. A., Tsuei, B., \& Ochoa, J. B. (2001). The routine use of sonography in penetrating torso injury is beneficial. Journal of Trauma and Acute Care Surgery, 51(2), 320-325.

7. Shanmuganathan, K., Killeen, K., Mirvis, S. E., \& White, C. S. (2000). Imaging of diaphragmatic injuries. Journal of thoracic imaging, 15(2), 104111.

8. Killeen, K. L., Mirvis, S. E., \& Shanmuganathan, K. (1999). Helical CT of diaphragmatic rupture caused by blunt trauma. AJR. American journal of roentgenology, 173(6), 1611-1616.

9. Nau, T., Seitz, H., Mousavi, M., \& Vecsei, V. (2001). The diagnostic dilemma of traumatic rupture of the diaphragm. Surgical endoscopy, 15(9), 992-996.

10. Mihos, P., Potaris, K., Gakidis, J., Paraskevopoulos, J., Varvatsoulis, P., Gougoutas, B., ... \& Lapidakis, E. (2003). Traumatic rupture of the diaphragm: experience with 65 patients. Injury, 34(3), 169-172.

11. Sadeghi, N., Nicaise, N., DeBacker, D., Struyven, J., \& Van Gansbeke, D. (1999). Right diaphragmatic rupture and hepatic hernia: an indirect sign on computed tomography. European radiology, 9(5), 972-974.

12. Kozak, O., Mentes, O., Harlak, A., Yigit, T., Kilbas, Z., Aslan, I., ... \& Bozlar, U. (2008). Late presentation of blunt right diaphragmatic rupture (hepatic hernia). The American journal of emergency medicine, 26(5), 638-e3.

13. Sattler, S., Canty, T. G., Mulligan, M. S., Wood, D. E., Scully, J. M., Vallieres, E., ... \& Karmy-Jones, R. (2002). Chronic traumatic and congenital diaphragmatic hernias: presentation and surgical management. Canadian respiratory journal, 9(2), 135-139. 